\section{Autosomal dominant polycystic kidney disease with liver involvement and left ventricular noncompaction: An unusual coexistence}

A male patient aged 63 years was admitted to the emergency department with shortness of breath, chest pain, and confusion. He had a history of chronic kidney disease owing to autosomal dominant polycystic kidney disease (ADPKD) with liver involvement (Fig. 1, Panels A and B). On admission, his physical examination revealed low blood pressure $(85 / 55 \mathrm{~mm} \mathrm{Hg})$, tachycardia (122 bpm.), jugular venous distention, muffled heart sounds, and clouding of consciousness. Electrocardiography showed sinus tachycardia with low voltages and signs of electrical alternans. Moreover, transthoracic echocardiography showed large pericardial effusion and right ventricle diastolic collapse. The patient underwent emergency pericardiocentesis. Thereafter, hemodialysis was performed owing to acute or chronic renal failure and metabolic acidosis. Detailed transthoracic echocardiography was performed after pericardiocentesis and revealed mild pericardial effusion, left ventricular noncompaction (LVNC) (Fig. 2, Panel A), and reduced ejection fraction. Coronary angiography (CAG) and left ventriculography (LVG) were performed to exclude coronary artery disease and confirm the diagnosis of LVNC. CAG showed normal coronary arteries, and LVG revealed LVNC (Fig. 2, Panel B). Finally, the patient was transferred to a nephrology clinic for a routine hemodialysis program.

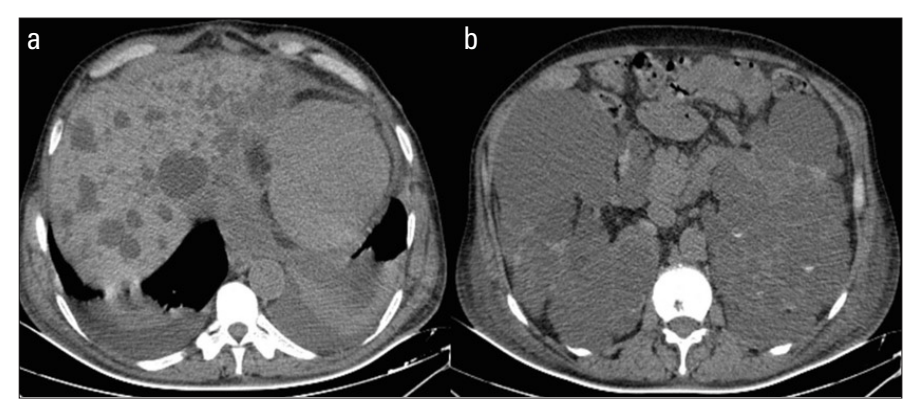

Figure 1. Panels $A$ and $B$ : autosomal dominant polycystic kidney disease with liver involvement seen on computed tomography

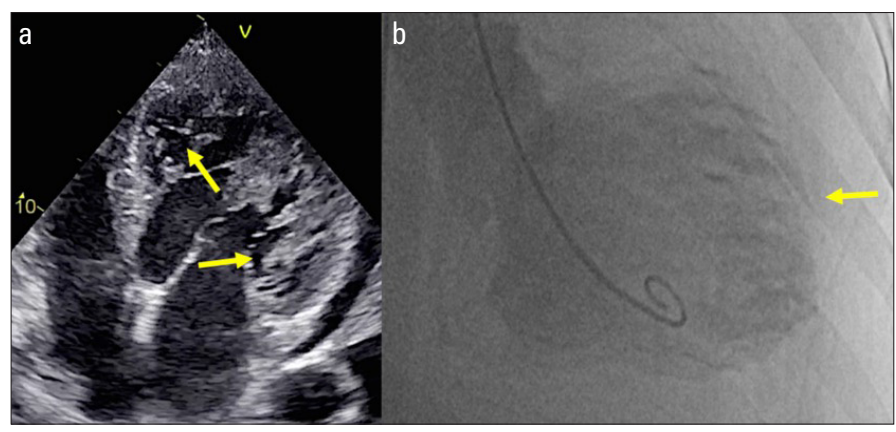

Figure 2. Panels $A$ and B: left ventricular noncompaction on transthoracic echocardiography and left ventriculography (arrows)

ADPKD is a hereditary disease characterized by kidney enlargement resulting from a progressive expansion of multiple cysts. PKD1 and PKD2, which encode polycystin 1 and polycystin 2, respectively, mutations are responsible for the development of ADPKD. LVNC is a rare form of cardiomyopathy characterized by prominent left ventricular trabeculae, deep intertrabecular recesses continuous with the left ventricular cavity, and a thin compacted layer. LVNC most commonly has X-linked recessive or autosomal dominant inheritance. Genes that encode mitochondrial function proteins (for example, taffazine) and other proteins associated with the cytoskeleton ( $\alpha$-dystrobrevin and dystrophin) are inherited as sex-linked recessive genes. In contrast, genes that encode sarcomere proteins or cytoskeletal proteins are inherited as autosomal dominant genes. The concomitant existence of ADPKD and LVNC is not frequently reported, and the association between these gene mutations is unknown.

Informed consent: Written informed consent was acquired from the patient for the publication.

\section{Aziz Inan Çelik (D), Tahir Bezgin (D, Metin Çağdaş (D) Department of Cardiology, Gebze Fatih State Hospital; Kocaeli-Turkey}

Address for Correspondence: Dr. Aziz Inan Çelik,

Gebze Fatih Devlet Hastanesi, Kardiyoloji Kliniği, Kocaeli-Türkiye Phone: +90 5532415923

E-mail: azizinanmd@hotmail.com

(C) Copyright 2021 by Turkish Society of Cardiology -

Available online at www.anatoljcardiol.com

DOI:10.5152/AnatolJCardiol.2021.66662 